05

\title{
Лазерно-индуцированные люминесцентные центры в алмазе: влияние экспозиции и длительности ультракоротких лазерных импульсов
}

\author{
(С) П.А. Данилов ${ }^{1}$, С.И. Кудряшов ${ }^{1}$, А.О. Левченко ${ }^{1}$, Е.А. Олейничук ${ }^{1}$, О.Е. Ковальчук ${ }^{2}$ \\ ${ }^{1}$ Физический институт им. П.Н. Лебедева, \\ 119991 Москва, Россия \\ ${ }^{2}$ Научно-исследовательское геологическое предприятие, АК „АЛРОСА“, \\ 678174 Мирный, Россия \\ e-mail: danilovpa@lebedev.ru
}

Поступила в редакцию 20.12.2021 г.

В окончательной редакции 20.12.2021 г.

Принята к публикации 30.12.2021 г.

\begin{abstract}
Исследованы оптические свойства точечных люминесцентных центров, сформированных в объеме природного алмаза ІаА-типа под действием ультракоротких лазерных импульсов видимого диапазона $(515 \mathrm{~nm})$ с длительностями $0.3-2.4 \mathrm{ps}$. Анализ с помощью конфокальной рамановской спектроскопии демонстрирует формирование азотно-вакансионных центров (NV) и отсутствие следов графитизации в области обработки. Амплитуда люминесценции NV-центров линейно зависит от времени экспозиции при различных длительностях ультракоротких лазерных импульсов.
\end{abstract}

Ключевые слова: ультракороткие лазерные импульсы, люминесценция, люминесцентные центры в алмазе, NV-центры.

DOI: $10.21883 / \mathrm{OS} .2022 .04 .52260 .50-21$

\section{Введение}

Точечные дефекты в диэлектриках и кристаллах, в том числе алмазе, сформированные под действием ультракоротких лазерных импульсов, находят применения в области квантовых технологий, оптической памяти и „невидимой“ лазерной микромаркировки, которая осуществляется без видимых повреждений образца [1-7]. Одним из самых хорошо изученных оптических дефектов в алмазах является отрицательно заряженный азотно-вакансионный центр (NV) с бесфононной линией (БФЛ) $638 \mathrm{~nm}[4]$. При этом о регистрации единичных NV-центров впервые сообщалось уже более 20 лет назад [5].

Метод прямой лазерной записи в диэлектриках ультракороткими лазерными импульсами хорошо показал себя и для записи различных структур в алмазах, в том числе одиночных NV-центров [6,7]. Для обнаружения оптически активных примесей и лазерно-индуцированных дефектов в алмазах активно применяется фотолюминесценция, которая позволяет также проанализировать природу электрон-фононного взаимодействия в кристалле при формировании точечных дефектов [8-12]. Детектирование одиночных NV-центров осуществимо с помощью конфокальной микроскопии, а для возбуждения их люминесценции эффективно использовать лазерные источники с длиной волны $~ 514 \mathrm{~nm}[8]$.

В настоящей работе представлены результаты лазерной записи ультракороткими импульсами с длиной волны $515 \mathrm{~nm}$ и длительностями $0.3-2.4 \mathrm{ps}$ точечных люминесцентных центров в объеме натурального алмаза при различных экспозициях 30-360 s с частотой следования лазерных импульсов $100 \mathrm{kHz}$, что соответствует числу импульсов в точку $N=(3-36) \cdot 10^{6}$. Сформированные массивы визуализированы и проанализированы c помощью сканирующей конфокальной рамановской спектроскопии, исследована зависимость выхода люминсценции точечных центров от экспозиции для различных длительностей лазерных импульсов.

\section{Экспериментальная часть}

Для обработки алмаза использовалось излучение второй гармоники $\left(\mathrm{B \Gamma}, \lambda_{\text {las }}=515 \mathrm{~nm}\right)$ волоконного фемтосекундного иттербиевого лазера Satsuma (Amplitude Systems) с максимальной энергией импульсов (без учета потерь в оптической схеме) $E_{\max }=3.6 \mu \mathrm{J} \quad$ в $\mathrm{TEM}_{00^{-}}$ моде и частотой следования $100 \mathrm{kHz}$. Длительность импульсов варьировалась в диапазоне $0.3-2.4$ ps при помощи встроенного компрессора. Лазерное излучение фокусировалось на глубину $\sim 200 \mu$ м микрообъективом (OB1, рис. 1) с числовой апертурой $\mathrm{NA}=0.25$, при этом размер пятна в воздухе в фокальной плоскости $R_{1 / e} \approx 2.2 \pm 0.2 \mu \mathrm{m}$. Образец закреплялся на трехкоординатной моторизированной платформе Standa (MS, рис. 1) с минимальным шагом перемещения $150 \mathrm{~nm}$.

Образец алмаза ІаА-типа представляет собой бесцветный прозрачный кубик со стороной $\sim 4 \mathrm{~mm}$. Для предварительной характеризации были измерены спектры пропускания в видимом $(200-1100 \mathrm{~nm})$ диапазоне длин 


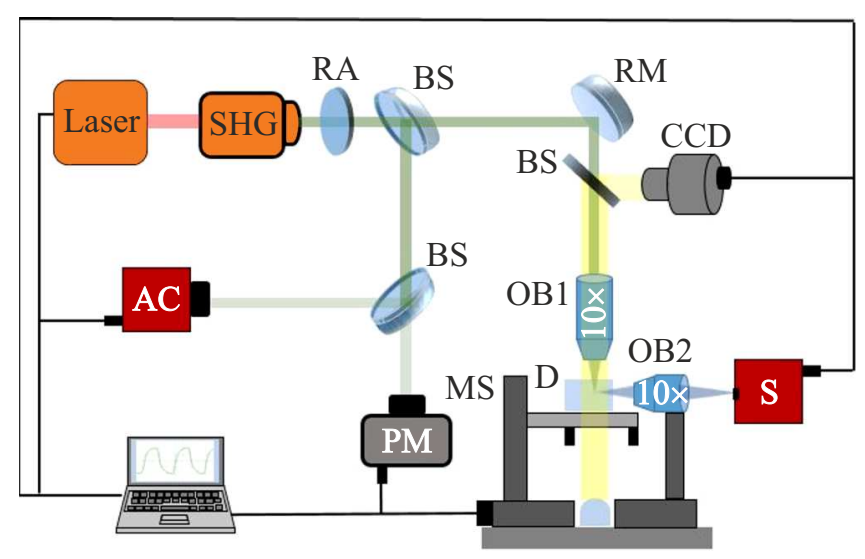

Рис. 1. Схема стенда для лазерной записи и регистрации люминесценции в алмазах: Laser - иттербиевый волоконный лазер $1030 \mathrm{~nm}$; SHG - генератор второй гармоники $515 \mathrm{~nm}$; $\mathrm{RA} \mathrm{-} \mathrm{дифракционный} \mathrm{ослабитель;} \mathrm{BS} \mathrm{-} \mathrm{делители} \mathrm{пучка;}$ RM - отражающее зеркало; РМ - измеритель мощности; $\mathrm{AC}$ - автокоррелятор; MS - трехкоординатная моторизованная платформа Standa; S - спектрометр Авеста ASP-150; $\mathrm{CCD}$ - камера CCD; OB1 - объектив накачки NA = $0.2510 \times$; $\mathrm{OB} 2-$ УФ объектив наблюдения $\mathrm{NA}=0.110 \times$; D - алмаз; PC - управляющий компьютер.

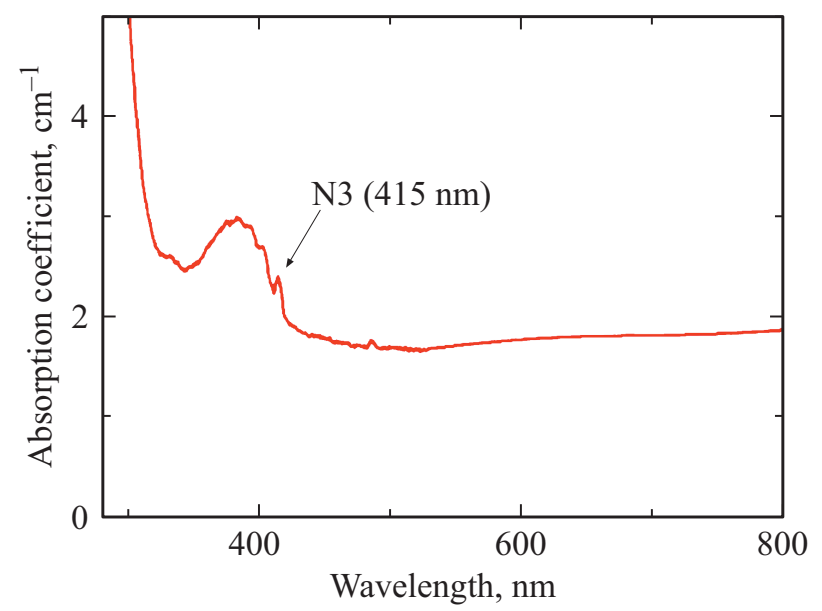

Pис. 2. Спектр поглощения алмаза в диапазоне длин волн $280-800 \mathrm{~nm}$.

волн при помощи спектрофотометра СФ-2000. Спектр поглощения, представленный на рис. 2, показывает наличие N3-центров $[4,8]$ в нашем образце.

Визуализация и анализ спектров люминесценции точечных дефектов, сформированных ультракороткими импульсами в объеме алмаза, осуществлялись с помощью 3D-сканирующего конфокального рамановского микроскопа Confotec MR350 с непрерывным лазером накачки $532 \mathrm{~nm}$ и охлаждаемой ПЗС-матрицей в качестве детектора. Для регистрации спектров применялась решетка $600 \mathrm{st} / \mathrm{mm}$, что позволяло получить разрешение $\sim 5 \mathrm{~cm}^{-1}$.

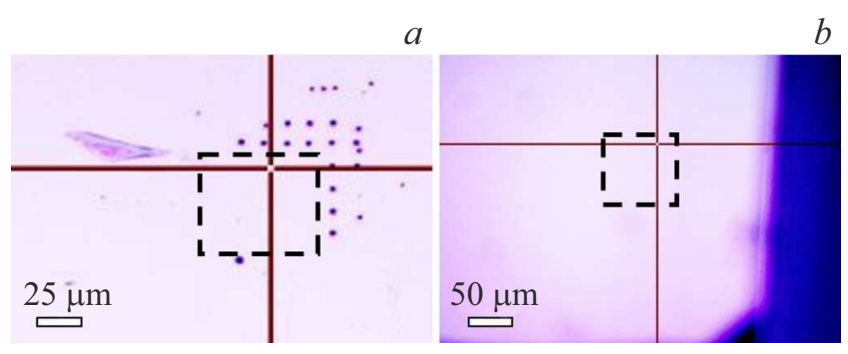

Рис. 3. Оптические снимки поверхности (a) и объема $(b)$ алмаза после обработки лазерными импульсами с длиной волны $515 \mathrm{~nm}$, длительностью $1 \mathrm{ps}$. Черной штриховой линией обозначена область, в которой была записана матрица точечных дефектов.

\section{Экспериментальные результаты и их обсуждение}

\section{Визуализация люминесцентных центров}

В нашей работе точечные дефекты в виде матрицы с варьируемой энергией $(60-600 \mathrm{~nJ})$ и временем экспозиции (30-360s) были сформированы на глубине $\sim 200 \mu \mathrm{m}$ в объеме алмаза под действием лазерных импульсов с длиной волны $515 \mathrm{~nm}$, длительностями $300 \mathrm{fs}, 1.0 \mathrm{ps}$ и $2.4 \mathrm{ps}$ с частотой повторения $100 \mathrm{kHz}$. Область обработки в первую очередь была проанализирована при помощи оптической микроскопии на предмет повреждений структуры алмаза при записи. На рис. 3 представлены снимки поверхности и объема алмаза после облучения лазерными импульсами с длиной волны $515 \mathrm{~nm}$ и длительностью 1 ps. Оптическими методами следов графитизации не обнаружено.

Далее при помощи сканирующей рамановской спектроскопии с накачкой $532 \mathrm{~nm}$ были получены флуоресцентные 2D-изображения сформированных дефектов (рис. 4). Для этого были просканированы области размером $\sim 150 \times 150 \mu \mathrm{m}$ с шагом $\sim 3 \mu \mathrm{m}$. Видно, что модифицированные области по яркости люминесценции значительно отличаются от необработанного алмаза, имеют хороший контраст.

\section{Спектроскопия}

Далее перейдем к рассмотрению спектральных особенностей сформированных матриц. На рис. 5, a представлен сравнительный спектр люминесценции необработанного алмаза (красная кривая) и точечного дефекта, сформированного при энергии в импульсе $450 \mathrm{~nJ}$, длительности $300 \mathrm{fs}$ и времени экспозиции $360 \mathrm{~s}$ (36 $10^{6}$ импульсов в точку). Видно, что в области 600-680 nm люминесценция после обработки возрастает в несколько раз. Также присутствует основная КР-линия алмаза $1331 \mathrm{~cm}^{-1}$ [4], что соответствует линии $\sim 572 \mathrm{~nm}$ в спектре люминесценции при накачке $532 \mathrm{~nm}$. На рис. 5, $b-d$ приведены разностные спектры 


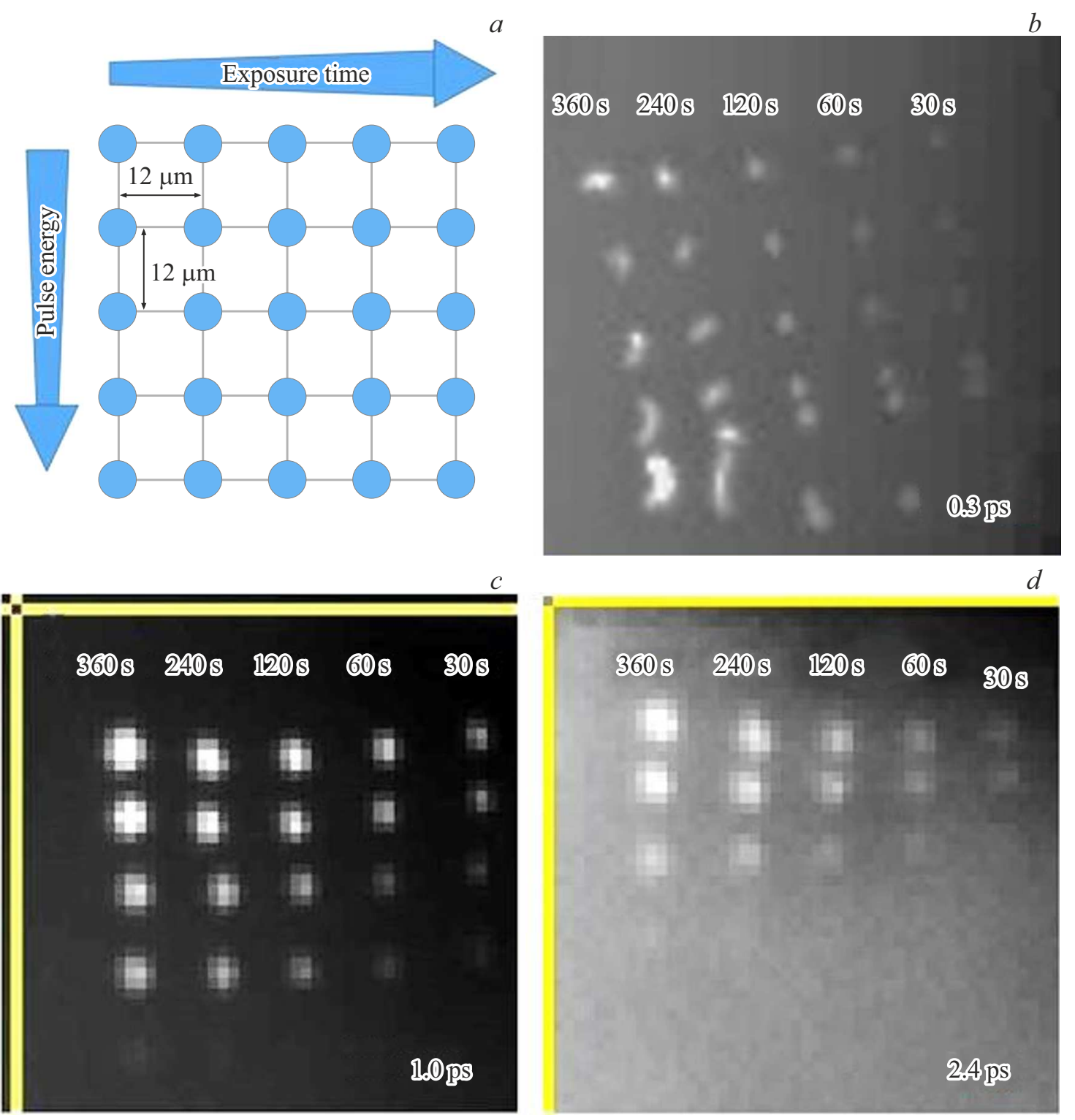

Рис. 4. Изображения люминесцентных центров в природном алмазе, полученные с помощью сканирующей рамановской спектроскопии с накачкой $532 \mathrm{~nm}$ и сформированных ультракороткими лазерными импульсами с длиной волны $515 \mathrm{~nm}$ на глубине $\sim 200 \mu \mathrm{m}$ с частотой следования $100 \mathrm{kHz}$ при различных экспозициях (указаны на рисунке) и энергиях в диапазоне 60-600 nJ. $a$ - схема записи точечных центров; $b$ - матрица, сформированная при длительности $300 \mathrm{fs} ; c-$ матрица, сформированная при длительности $1.0 \mathrm{ps} ; d$ - матрица, сформированная при длительности $2.4 \mathrm{ps}$.

за вычетом усредненного фона для разных времен экспозиции и энергии в импульсе $\sim 300 \mathrm{~nJ}$.

Заметно, что с увеличением экспозиции люминесценция точечных дефектов усиливается и имеет максимум в области $\sim 640 \mathrm{~nm}$. Данный максимум, по-видимому, связан с формированием отрицательно заряженных NVцентров $[4,9]$, однако в нашем случае свойственная им БФЛ $\sim 638 \mathrm{~nm}[4]$ не наблюдается. Также стоит отметить, что наибольшая амплитуда люминесценции характерна для центров, сформированных при длительности лазерного излучения $1.0 \mathrm{ps}$.

Далее была исследована зависимость выхода люминесценции (по максимуму амплитуды) сформированных точечных центров при различных длительностях лазерных импульсов. В целом для всех энергий лазерного излучения зависимости имеют схожий характер. На рис. 6 приведены графики выхода люминесценции (по максимуму амплитуды) для энергий 150 и $300 \mathrm{~nJ}$ в зависимости от числа импульсов. Видно, что в обоих случаях зависимость носит линейный характер.

\section{Заключение}

Исследовано лазерно-индуцированное формирование точечных люминесцентных центров в природном ал- 

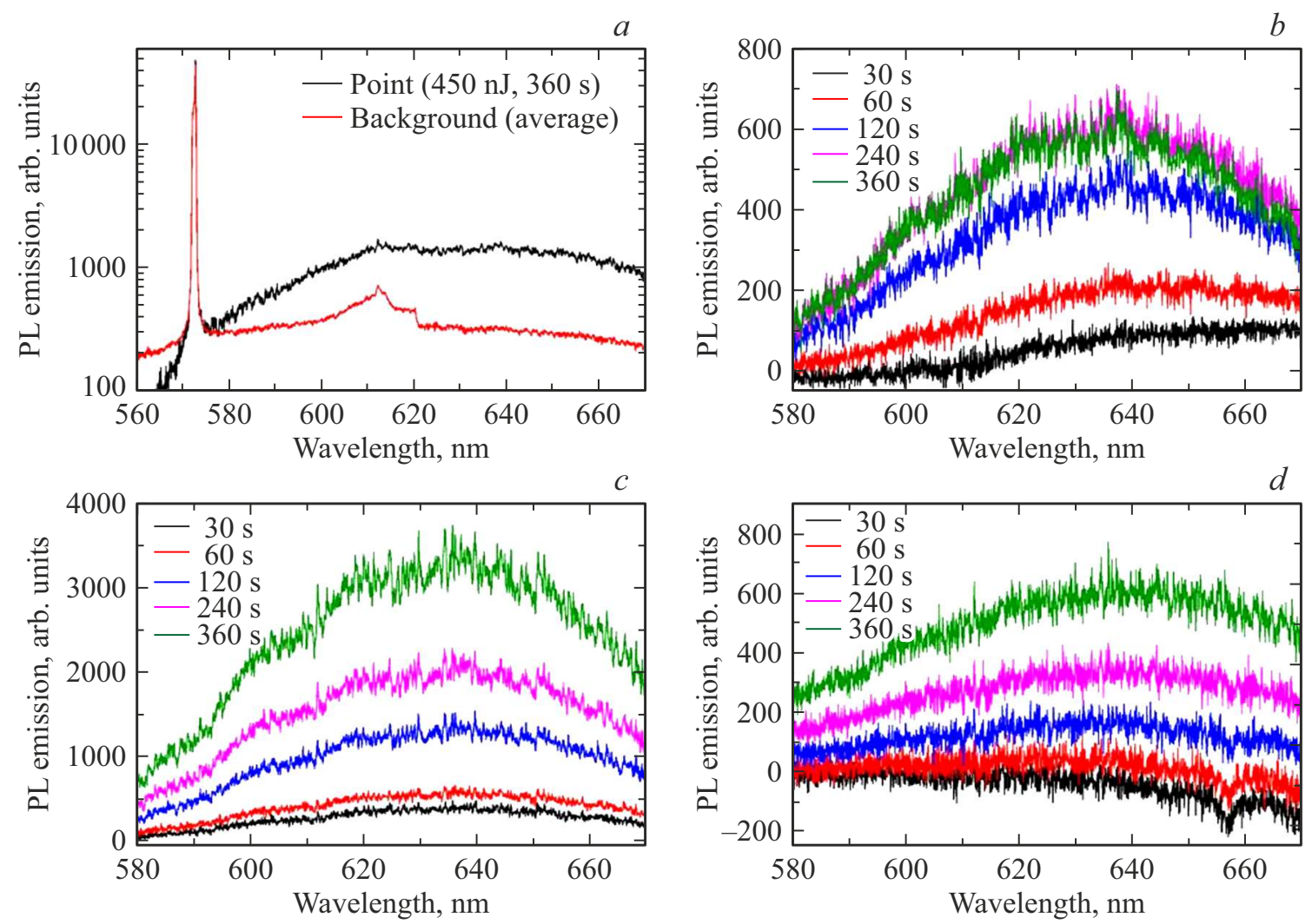

Рис. 5. Спектры люминесценции точечных дефектов в природном алмазе для разных экспозиций и энергии в импульсе $300 \mathrm{~nJ}$ при накачке лазером с длиной волны $532 \mathrm{~nm} . a-$ спектр люминесценции немодифицированного алмаза и метки $(450 \mathrm{~nJ}, 300 \mathrm{fs}, 360 \mathrm{~s})$; $b$ - люминесценция точечных дефектов за вычетом фона для различных экспозиций лазерного излучения $(30,60,120,240,360 \mathrm{~s})$ и длительности импульсов $300 \mathrm{fs} ; c$ - люминесценция точечных дефектов за вычетом фона для различных экспозиций лазерного излучения $(30,60,120,240,360 \mathrm{~s})$ и длительности импульсов $1.0 \mathrm{ps} ; d$ - люминесценция точечных дефектов за вычетом фона для различных экспозиций лазерного излучения $(30,60,120,240,360 \mathrm{~s})$ и длительности импульсов $2.4 \mathrm{ps}$.
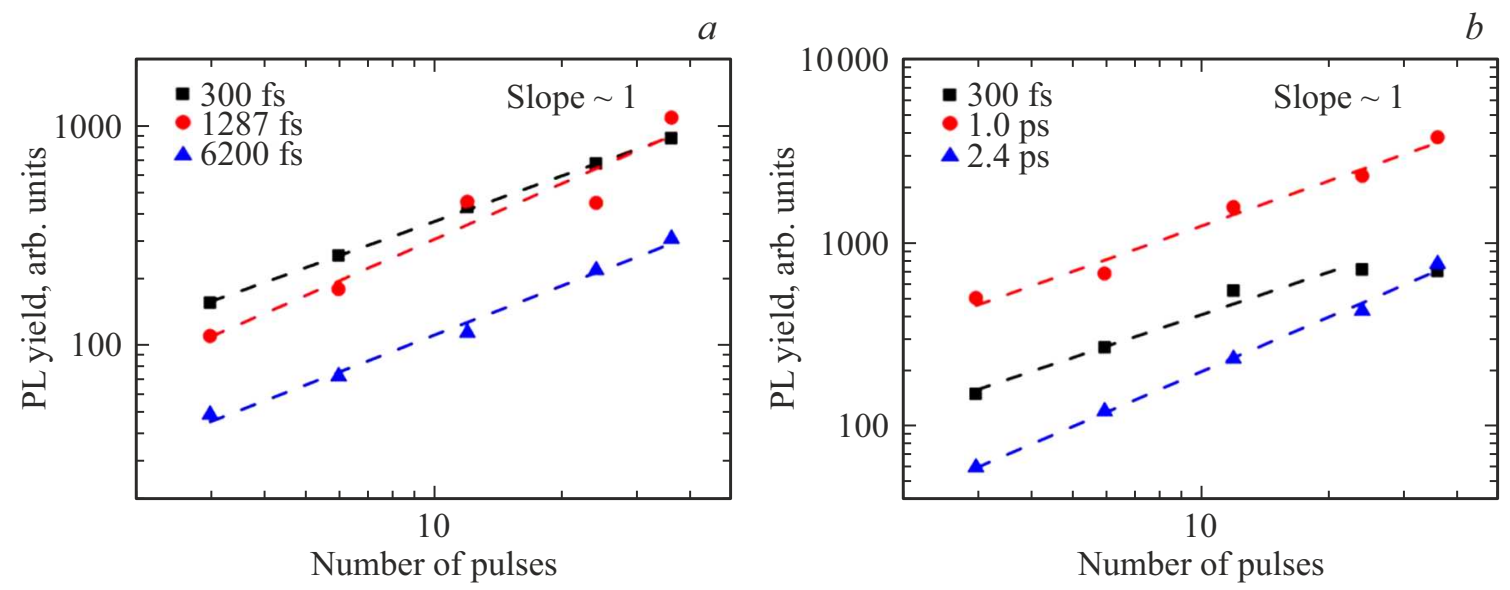

Рис. 6. Выход люминесценции по максимуму амплитуды точечных люминесцентных центров в природном алмазе в зависимости от числа лазерных импульсов (экспозиции) для двух энергий: $150(a)$ и $300 \mathrm{~nJ}(b)$.

мазе ІаА-типа под действием ультракоротких импульсов с длиной волны $515 \mathrm{~nm}$, длительностями $0.3-$ $2.4 \mathrm{ps}$ при различных экспозициях лазерного излучения $N=(3-36) \cdot 10^{6}$ импульсов в точку. Установлено, что под действием лазерного излучения формируются отрицательно заряженные NV-центры, люминесценция которых имеет наибольшее значение при формировании лазерными импульсами с длительностью 1 ps. Выход люминесценции точечных дефектов (NV) по максимуму $\sim 640 \mathrm{~nm}$ для различных длительностей лазерного 
излучения в зависимости от экспозиции при энергиях накачки до $600 \mathrm{~nJ}$ имеет линейный характер. Лазерная запись люминесцентных меток представляется многообещающим методом микромаркировки алмазов ввиду отсутствия видимых повреждений (графитизации) в области воздействия лазерного излучения.

\section{Финансирование работы}

Исследование выполнено за счет гранта Российского научного фонда (проект № 21-79-30063).

\section{Конфликт интересов}

Авторы заявляют, что у них нет конфликта интересов.

\section{Список литературы}

[1] F. Jelezko, T. Gaebel, I. Popa, M. Domhan, A. Gruber, J. Wrachtrup. Phys. Rev. Lett., 93 (13), 130501 (2004). DOI: 10.1103/PhysRevLett.93.130501.

[2] W. Pfaff, B.J. Hensen, H. Bernien, S.B. Van Dam B., M.S. Blok, T.H. Taminiau, M.J. Tiggelman, R.N. Schouten, M. Markham, D.J. Twitchen, R. Hanson. Science, 345 (6196), 532 (2014). DOI: 10.1126/science.1253512.

[3] B. Lounis, M. Orrit. Rep. Prog. Phys., 68(5), 1129 (2005). DOI: https://doi.org/10.1088/0034-4885/68/5/R04.

[4] A.M. Zaitsev. Optical properties of diamond: a data handbook (Springer Science \& Business Media, Berlin/Heidelberg, 2013).

[5] A. Gruber, A. Dräbenstedt, C. Tietz, L. Fleury, J. Wrachtrup, C. Von Borczyskowski. Science, 276 (5321), 2012 (1997). DOI: $10.1126 /$ science. 276.5321 .2012 .

[6] Y.C. Chen, B. Griffiths, L. Weng, S.S. Nicley, S.N. Ishmael, Y. Lekhai, J.M. Smith. Optica, 6(5), 662 (2019). DOI: https://doi.org/10.1364/OPTICA.6.000662.

[7] B. Sotillo, V. Bharadwaj, J.P. Hadden, M. Sakakura, A. Chiappini, T.T. Fernandez, S. Longhi, O. Jedrkiewicz, Y. Shimotsuma, L. Criante, R. Osellame, G. Galzerano, M. Ferrari, K. Miura, R. Ramponi, P.E. Barclay, S.M. Eaton. Sci. Rep., 6 (1), 1 (2016). DOI: https://doi.org/10.1038/srep35566.

[8] F. Jelezko, C. Tietz, A. Gruber, I. Popa, A. Nizovtsev, S. Kilin, J. Wrachtrup. Single Mol., 2(4), 255 (2001). DOI: 10.1002/1438-5171(200112)2:4<255::AIDSIMO255>3.0.CO;2-D.

[9] A.T. Collins. Diamond Relat. Mater., 1 (5-6), 457 (1992). DOI: https://doi.org/10.1016/S0925-9635(99)00314-3.

[10] С.И. Кудряшов, А.О. Левченко, П.А. Данилов, Н.А. Смирнов, А.Е. Рупасов, Р.А. Хмельницкий, О.Е. Ковальчук, А.А. Ионин. Письма в ЖЭТФ, 112 (9), 553 (2020). DOI: https://doi.org/10.31857/S1234567820210016.

[S.I. Kudryashov, A.O. Levchenko, P.A. Danilov, N.A. Smirnov, A.E. Rupasov, R.A. Khmel'nitskii, O.E. Koval'chuk, A.A. Ionin. JETP Letters, 112 (9), 553 (2020). DOI: https://doi.org/10.1134/S0021364020210080].

[11] S.I. Kudryashov, P.A. Danilov, N.A. Smirnov, A.O. Levchenko, M.S. Kovalev, Y.S. Gulina, O.E. Kovalchuk, A.A. Ionin. Opt. Mater. Express, 11 (8), 2505 (2021).

DOI: https://doi.org/10.1364/OME.427788.
[12] V.V. Kononenko, I.I. Vlasov, V.M. Gololobov, T.V. Kononenko, T.A. Semenov, A.A. Khomich, V.A. Shershulin, V.S. Krivobok, V.I. Konov. Appl. Phys. Lett., 111 (8), 081101 (2017). DOI :https://doi.org/10.1063/1.4993751. 